\title{
Mapeamento da produção científica e participação dos autores nos anais do ENANCIB: uma análise a partir da correlação entre as redes de coautoria e redes de participação nos grupos de trabalho
}

\author{
Dalton Lopes Martins \\ dmartins@gmail.com \\ Universidade de São Paulo
}

\begin{abstract}
Resumo: Os eventos científicos são importantes espaços de articulação dos pesquisadores em suas áreas do conhecimento. Relações sociais de coautoria na produção científica e participação em determinados grupos de trabalho na apresentação oral e divulgação em painéis representam tipos de relação que podemos modelar como redes sociais e analisar seus padrões em busca de entender como uma comunidade científica se articula. O presente trabalho analisa os anais do Encontro Nacional de Pesquisa em Ciência da Informação (ENANCIB), propondo um estudo de análise de redes que integre o mapeamento dos principais padrões das redes de coautoria e participação de pesquisadores em grupos de trabalho. Utilizamos a análise de redes sociais e a correlação de indicadores de centralidade com os dados descritivos dos anais para identificar possíveis características e eventos geradores dessas redes. Resultados apontam que a articulação entre pesquisadores se dá mais em âmbito local em seus componente de rede do que no âmbito de seus pares presentes nos grupos de trabalho por onde circulam.
\end{abstract}

Palavras-chave: coautoria; produção científica; ENANCIB; análise de redes sociais; centralidade.

Abstract: The scientific events are important spaces of articulation of the researchers in their fields of knowledge. Social relations of co-authorship in scientific production and participation in certain working in the oral presentation and panels represent types of relationship that we can model using social networks and analyze their patterns of seeking to understand how a scientific community is divided. This paper analyzes the proceedings of Encontro Nacional de Pesquisa em Ciência da Informação (ENANCIB) proposing a study of network analysis that integrates the mapping of the major patterns of co-authorship networks of researchers and participation in working groups. We use social network analysis and correlation of indicators of centrality and the descriptive data of the proceedings to identify possible features and events generating these networks. Results indicate that the relationship between researchers happens more in the local component in their network than within their peer groups.

Keywords: co-authoring; scientific production; ENANCIB; social network analysis; centrality.

\section{INTRODUÇÃO}

A análise da produção científica de um determinado campo do conhecimento, área temática ou mesmo assuntos específicos tem sido uma ferramenta fundamental no sentido de se perceber ou não a ocorrência de estruturas, tendências, dinâmicas e movimentos sociais que podem estar expressos nessa produção, seja analisada de forma específica ou em estudos comparados com outras áreas, temas e assuntos. A identificação ou não de diferentes movimentos em torno dessa 
produção torna-se, portanto, uma forma de conhecer e avaliar a relevância em termos do impacto dessa produção, sua repercussão, sua abrangência, pessoas e instituições envolvidas, recursos mobilizados, articulações em construção, bem como diferentes características que podem ser analisadas a depender da qualidade, da quantidade e da abrangência dos dados que tem-se condições de avaliar.

É a cientometria uma área da Ciência da Informação que fornece diferentes métodos que permitem avaliar os aspectos quantitativos da produção científica, permitindo relacioná-los com outros aspectos qualitativos, facilitando a constituição de melhores mapas do conhecimento, ampliando a capacidade de entendimento dos modos como essa produção tem se desenvolvido, suas diferentes formas de apropriação e políticas eventualmente envolvidas. De forma a tratar os aspectos quantitativos de forma empírica, os métodos da cientometria podem ser aplicados para tratar 3 principais questões (Leydesdorff, 2001): (i) o quanto cada variável é responsável pelos aspectos variantes dessa produção, (ii) os efeitos de agregação e desagregação dessas variáveis em outros níveis de análise e (iii) o modelo de desenvolvimento dinâmico dessa produção. Glänzel e Thijs (2011) sugerem três movimentos paradigmáticos que podem ser entendidos como movimentos de emergência de novos tópicos de interesse em meio ao universo atual de assuntos em discussão: o crescimento excepcional de um determinado tema em relação aos demais, surgimento de um tema completamente novo originado de temas anteriores e a mudança de enfoque e um tema atual. Os três movimentos refletem tendências que podem ser identificadas a partir da análise da produção científica de uma ou diversas áreas do conhecimento, dependendo do interesse específico que se deseja investigar.

Já a comunicação científica é um processo essencialmente social, envolvendo múltiplas formas de relação e níveis de interação entre pesquisadores, através do que podemos considerar como relações formais ou informais. Segundo Pisciotta (2006), há 3 categorias básicas de comunicação científica na atualidade: a comunicação formal abarcando a comunicação escrita (relatórios, livros, periódicos, revisões e outros), a comunicação informal consolidada na comunicação oral (reuniões científicas, participações em associações profissionais e colégios invisíveis) e a comunicação eletrônica, que termina por auxiliar na manutenção dos canais informais, mesmo sendo escrita.

Sem dúvida, essa divisão entre comunicação formal e informal permite classificarmos a estrutura ou arquitetura de participação (BUFREM, GABRIEL JUNIOR e GONÇALVES, 2010) como o modo pelo qual a comunicação ocorre, sabendo que essa arquitetura se consolida de modo integrado, havendo influência da comunicação informal naquilo que é produzido na formal e vice- 
versa, constituindo um intenso fluxo contínuo de informação pelos diferentes modos que ocorre a comunicação, terminando por afetar de modo geral as pessoas que produzem e participam dessa comunicação científica. São essas relações que determinam e são determinadas por um campo de articulação entre seus participantes, constituindo espaços por onde as ideias fluem, influências de pesquisa e tendências de pensamento circulam, trocas de experiências são estabelecidas, caracterizando arquiteturas de colaboração entre pesquisadores que quando identificados como um grupo em uma área específica do conhecimento culminam naquilo que têm sido chamado de colégios invisíveis.

Vanz e Stumpf (2010) relatam como na ideia de Solla Price, um importante pesquisador sendo um dos responsáveis pelo uso atual do conceito de colégios invisíveis, a colaboração científica acontece no âmbito desses colégios:

\begin{abstract}
“... as comunidades informais de pesquisadores que se comunicam, trocam informações e experiências e também publicam formalmente seus resultados de pesquisa. A afirmação baseou-se em estudos empíricos demonstrando que os pesquisadores encontram-se em congressos, conferências, reuniões sobre suas especialidades e visitam-se por meio de intercâmbios institucionais. Nessas oportunidades, os cientistas trocam ideias e preprints, discutem projetos de pesquisa, e, como consequência da interação, constituem um grupo que detém o controle e administração de fundos de pesquisa e laboratórios."
\end{abstract}

Vale ressaltar na afirmação acima essa correlação direta entre o que podemos aqui chamar de comunicação formal e informal, dando evidência para o importante papel que exerce nessa lógica de constituição dos colégios invisíveis os congressos, conferências e reuniões científicas sobre as especialidades de um determinado grupo de pesquisadores. São nesses espaços que ocorrem importantes articulações entre os pesquisadores, determinando o direcionamento de fundos de pesquisa e, por sua vez, os principais temas e focos de interesse onde essa pesquisa será realizada.

Além disso, como ressalta Meadows (1999), as conversas que ocorrem nos eventos científicos onde são realizadas comunicações orais de trabalhos acadêmicos possuem inúmeras virtudes que são resumidas pelas seguintes características: retroalimentação imediata, informação adaptada ao receptor, implicações explicitadas, e conhecimento prático transmitido junto com conhecimento conceitual. Mais uma vez, temos aqui características que evidenciam como esses espaços de promoção de articulação entre os pesquisadores possuem um papel fundamental em seu próprio processo de produção científica.

Dado esse cenário inicial, os colégios invisíveis terminam por se constituir, em muitos casos, em associações formais de pesquisa, sendo elas responsáveis por organizarem periodicamente 
encontros entre pesquisadores, sistematizando e garantindo que esses espaços de articulação possam continuamente existir para a boa manutenção da área como campo do conhecimento. Segundo Carmo e Prado (2005), essas associações estabelecem normas para a realização desses encontros, propondo estruturas onde os participantes submetem trabalhos para avaliação pelos seus pares, os quais após apreciação podem ser rejeitados ou sugeridos para apresentação nas modalidades comunicação oral ou exposição de painel. Além disso, dependendo do tamanho dessas associações científicas e do formato desses encontros, eles podem ser organizados por Grupos de Trabalho temáticos, garantindo espaços específicos para que determinados subtemas de uma área possam ser devidamente representados.

Logo, temos na proposta de formato desses encontros a relação direta entre a comunicação científica formal e informal, considerando que os pesquisadores que realizam as comunicações orais de seus trabalhos e apresentação de seus painéis irão se encontrar num mesmo de grupo de trabalho, estabelecendo relações informais nos debates e conversas ali realizados a partir de trabalhos formais que ali são apresentados. Temos aqui o encontro de dois modos de relacionamento social na comunicação científica: a relação de coautoria entre os produtores de comunicação científica formal e as relações de participação em um determinado grupo de trabalho de um evento científico onde os trabalhos dos coautores serão apresentados. É importante ressaltar que a realização desses eventos de modo contínuo ao longo do tempo, considerando que haja intensa participação dos pesquisadores de uma determinada associação de pesquisa, manifestam o campo onde ocorre a articulação entre esses pesquisadores, seus principais padrões de conexão e apropriação dos grupos de trabalho como espaços de relacionamento social a partir de sua produção científica. Analisar como essas relações ocorrem é observar de um lugar privilegiado o modo como um grupo de pesquisadores se articula.

Considerando que essas relações sociais de coautoria e participação podem ser estudadas e analisadas se as modelarmos como redes sociais e se tivermos o "entendimento de que, por meio da configuração das redes sociais e dos elos entre os atores, é possível analisar o comportamento individual e coletivo de seus membros" (MARTELETO, 2010) surge aqui as nossas perguntas de pesquisa que pretendemos trabalhar no presente artigo. Que estratégias de conectividade podem ser identificadas entre os pesquisadores participantes de um evento científico a partir da análise integrada das redes de coautoria dos trabalhos ali aceitos para apresentação e das redes de participação em grupos de trabalho? Que possíveis relações existem entre essas duas estruturas de redes? E, por fim, que relações podemos estabelecer entre essas redes e a arquitetura de participação proposta por um evento científico? 
De modo a tratar essas questões, organizamos o trabalho do seguinte modo: a seção 2 apresenta os principais conceitos da análise de redes sociais que serão utilizados para modelarmos os dois tipos de redes sociais comentados acima, a seção 3 apresenta o Encontro Nacional de Pesquisa em Ciência da Informação (ENANCIB), evento científico que escolhemos como estudo de caso de nossa análise, a seção 4 apresenta a metodologia utilizada neste estudo, considerando o modo como os anais do evento foram tratados e modelados para a realização de nossa análise, a seção 5 apresenta os resultados encontrados, a seção 6 apresenta as considerações finais e, por fim, a seção 7 as referências bibliográficas utilizadas.

\section{MODELAGEM DAS RELAÇÕES: CONCEITOS DA ANÁLISE DE REDES SOCIAIS}

As redes sociais são modeladas através da determinação dos elementos sociais que consideramos como sendo os seus nós e dos tipos de eventos que são representados pelas conexões entre esses nós. Wasserman e Faust (1994, pag. 29) propõem que podemos classificar as redes em termos de modos, mais especificamente como modo 1 e modo 2 , sendo que a diferença entre eles definiria o conjunto de entidades que podem ser modelados como nós de uma rede.

Explicando melhor, a modelagem de uma rede modo 1 é composta por apenas um único tipo de nó, por exemplo, pesquisadores que são coautores de artigos científicos e que tiveram seus trabalhos aprovados para apresentação em um evento. Já a modelagem de uma rede modo 2 é composta por dois tipos de nós, por exemplo, um tipo seria os grupos de trabalho que existem na organização de um evento científico e o outro tipo seria os pesquisadores que se afiliaram a um grupo ao apresentarem um trabalho científico no mesmo.

Os dois modos de modelarmos redes sociais podem ser utilizados para representarmos diferentes tipos de relações sociais. O modo 1 é utilizado para representar qualquer tipo de relação que ocorra de modo direto entre os atores de uma rede. Já o modo 2 é utilizado para representar relações de afiliação, onde o conjunto de atores da rede (representando um dos conjuntos de nós) se afilia a um determinado tipo de evento (representando o outro conjunto de nós) (NOOY, MRVAR e BATAGELJ, 2005, pag. 103), que pode ser a participação em um clube, a adesão a um partido político ou a participação em um grupo de trabalho específico.

Já partindo para medidas que caracterizam os nós da rede e que serão utilizadas para analisarmos as redes neste trabalho, utilizaremos aqui o conceito de centralidade. A medida de 
centralidade tem por objetivo investigar quais seriam os atores mais importantes que estão presentes em uma rede. A hipótese utilizada para o grau de importância de um ator é de que quanto mais relações e articulação de relações um ator tenha numa rede, mais importante ele é para o padrão estrutural que é denotado pela rede (WASSERMAN e FAUST, 1994, p. 169).

Há três medidas que são utilizadas para o cálculo de centralidade dos nós: centralidade por grau, centralidade por intermediação (betweenness) e centralidade por proximidade (closeness) (FELLMAN e WRIGHT, 2008, p. 145).

A centralidade por grau representa o número de linhas incidentes em um nó da rede, ou seja, o número de conexões diretas que um determinado ator estabelece dentro de sua rede. $\mathrm{A}$ fórmula da centralidade por grau é apresentada na fórmula 1, onde $d(n i)$ representa a proporção de vértices que estão conectados ao nó que desejamos calcular a centralidade, e $\boldsymbol{g}$ representa o número de vértices totais da rede.

$$
C_{D}\left(n_{i}\right)=d\left(n_{i}\right) / g-1
$$

Fórmula 1: Centralidade por grau

A centralidade por intermediação (betweenness) representa a habilidade de um indivíduo de se conectar aos círculos importantes da rede (FELLMAN e WRIGHT, 2008, p. 145). A intermediação é uma característica "entre", que denota o grau de centralidade que um vértice se encontra em relação as principais rotas por onde os fluxos informacionais de uma rede são estabelecidos. A fórmula da centralidade por intermediação é apresentada na fórmula 2. É calculada com base na probabilidade de que a comunicação entre o ator $\boldsymbol{j}$ e o ator $\boldsymbol{k}$ tomem o mesmo caminho na rede. 0 membro $g_{j k}$ representa o número de caminhos mais curtos que existem entre dois atores na rede. Lembrando que podem existir diversos caminhos que conectam dois atores quaisquer numa rede, o caminho mais curto é o menor número de linhas que precisam ser atravessadas para se chegar de um ator ao outro. Pode existir mais de um caminho entre dois atores que sejam os mais curtos entre eles, contendo o menor número de passos cada um. O membro $g_{j k}\left(n_{i}\right)$ representa o número de caminhos mais curtos que interliga dois atores e que passam pelo ator $i$, o qual estamos calculando a centralidade por intermediação.

$$
C_{B}\left(n_{i}\right)=\sum_{j<k} g_{j k}\left(n_{i}\right) / g_{j k}
$$


Figura 2. Centralidade por intermediação

A centralidade por proximidade (closeness) representa a habilidade de um indivíduo monitorar o fluxo de informação e enxergar o que está acontecendo na rede (FELLMAN e WRIGHT, 2008, p. 145). A proximidade é uma característica "com", que denota o grau de centralidade (o quão próximo), que um vértice se encontra em relação aos principais atores que estabelecem os fluxos de uma rede. A fórmula da centralidade por intermediação é apresentada na fórmula 3. O membro $d\left(n_{i}, n_{j}\right)$ representa o número de linhas que existem no menor caminho que conecta o nó $\boldsymbol{i}$ e $\boldsymbol{j}$ dentro da rede.

$$
C_{C}\left(n_{i}\right)=1 /\left[\sum_{j=1}^{g} d\left(n_{i}, n_{j}\right)\right]
$$

Fórmula3: Centralidade por proximidade

\section{O ENANCIB}

O ENANCIB é o Encontro Nacional de Pesquisa em Ciência da Informação, evento que vem ocorrendo desde o ano de 1994, já tendo sido realizadas 12 edições, sendo a última em outubro de 2011, na cidade de Brasília. O evento é realizado como uma das frentes de atuação da Associação Nacional de Pesquisa e Pós-graduação em Ciência da Informação (ANCIB), sendo considerado um "fórum de debates e reflexões que reúne pesquisadores interessados em temas especializados da Ciência da Informação, organizados em Grupos de Trabalho" (ANCIB, 2012). Segundo o Instituto Brasileiro de Informação em Ciência e Tecnologia (IBICT):

\footnotetext{
"Pela sua história, os ENANCIBs têm se constituído em foro privilegiado de apresentação e discussão da pesquisa científica na área da Ciência da Informação Brasileira, congregando o conjunto dos pesquisadores e dos programas de pósgraduação nacionais nesse domínio da Ciência. As onze edições já realizadas têm possibilitado identificar o estado da arte da área, suas frentes de pesquisa, temas de interesse e lacunas de pesquisa a serem preenchidas" (IBICT, 2012).
}

Até o presente momento, existem 11 grupos de trabalho que são construídos pelos pesquisadores da área como espaços temáticos e fóruns privilegiados para suas discussões, debates e apresentações de resultados de pesquisas dentro do seu contexto temático. Os grupos são 
denominados: GT 1 - Estudos Históricos e Epistemológicos da Ciência da Informação, GT 2 Organização e Representação do Conhecimento, GT 3 - Mediação, Circulação e Apropriação da Informação, GT 4 - Gestão da Informação e do Conhecimento nas Organizações, GT 5 - Política e Economia da Informação, GT 6 - Informação, Educação e Trabalho, GT 7 - Produção e Comunicação da Informação em CT\&I, GT 8 - Informação e Tecnologia, GT 9 - Museu, Patrimônio e Informação, GT 10 - Informação e Memória, GT 11 - Informação \& Saúde.

Os grupos de trabalho do ENANCIB, mais do que espaços de divulgação da produção científica temática, representam para fins de nossa pesquisa espaços de encontro e relacionamento entre os pesquisadores, considerando que a participação dos mesmos em um grupo de trabalho quando da submissão de sua comunicação oral determina seu interesse em fazer parte deste grupo, comunicar sua pesquisa para os outros pesquisadores que supõem ali encontrar, recebendo críticas, contribuições e reconhecimento pelo seu trabalho realizado. A relevância do evento para a área, como acima apresentamos, permite inferirmos que os grupos de trabalho agregam os pesquisadores que atuam no estado de arte em seu eixo temático, criando oportunidades de relacionamento social favoráveis para os pesquisadores da área.

Logo, os 11 grupos de trabalho do ENANCIB se tornam elementos de agregação social privilegiados para a área da Ciência da Informação no Brasil, sendo, portanto, espaços singulares para analisarmos as estratégias de articulação na produção científica desses pesquisadores.

\section{METODOLOGIA}

A base de dados dos anais do ENANCIB disponibilizada para consulta online no site da Associação Nacional de Pesquisa e Pós-graduação em Ciência da Informação (ANCIB, 2012) foi utilizada como fonte de informação pelo fato de disponibilizar a data, o grupo de trabalho, o título e o nome dos autores que tiveram seus trabalhos publicados nos anais do evento. O estudo tem por objetivo demonstrar a forma como se constituiu ao longo dos anos de realização do ENANCIB as redes de coautoria entre seus autores e as redes de participação desses mesmos autores nos respectivos grupos de trabalho onde apresentaram seus trabalhos, além de mostrar as possíveis correlações existentes entre esses dois tipos de redes e as posições ocupadas nessas duas formas de visualização, nos auxiliando, dessa forma, a entendermos melhor as estratégias de conectividade e participação utilizadas pelos autores em suas participações.

Para tanto, precisávamos identificar para cada trabalho publicado que relações de coautoria existiram e no âmbito de que grupo de trabalho as mesmas ocorreram, o que pode ser facilmente 
identificado pelos dados disponíveis nos anais online coletados. De modo a facilitar a realização do estudo e permitir gerarmos os cruzamentos de dados necessários a avaliação em questão, construímos uma base de dados estruturada com os seguintes campos:

- identificação do trabalho: número único que identificava de forma exclusiva cada trabalho disponível nos anais;

- nome do autor: o nome de cada autor participante de um trabalho foi organizado em registros separados, permitindo contabilizarmos a quantidade de autores por artigo, artigos por grupo de trabalho, autores por grupo de trabalho, entre outros indicadores que apresentaremos na seção de resultados;

- numero do autor: atribuímos a cada autor uma chave numérica única, de forma a facilitar o processo de normalização dos nomes em seus vários modos possíveis de escrita.

- grupo de trabalho: para cada trabalho publicado, atribuímos a qual grupo cada registro individual pertencia;

- ano: para cada trabalho publicado, atribuímos a qual ano, logo edição do ENANCIB, ele foi publicado.

A partir da construção dessa base de dados e a carga da informação coletada dos anais online do site da ANCIB, inicialmente descrevemos como esses dados estão estruturados, buscando evidenciar a quantidade de grupos de trabalho por ano do evento, a quantidade de autores, a quantidade de trabalhos publicados, bem como a distribuição dos trabalhos em quantidade de coautores. Esses dados nos permitiram visualizarmos de modo geral como os autores se distribuíram pelos grupos de trabalho e sua produção, sendo fonte de informação que nos permitirá analisar como influenciam nas características das redes sociais modo 1 e modo 2 desses autores.

Em seguida, construímos as redes de coautoria, considerando as conexões estabelecidas entre os autores ao longo de todos os anos, e as redes de participação nos grupos de trabalho, considerando as participações que cada autor realizou nos diferentes grupos onde apresentou um trabalho durante todo o período de tempo em análise. Para visualização dessas duas redes, utilizamos como atributos de cor dos nós o número de grupos que um autor participou e de tamanho dos nós a sua centralidade por grau, facilitando identificarmos visualmente que posições ocupam os nós que mais participaram de grupos de trabalho e sua influência na estrutura das redes.

Por fim, para analisarmos as possíveis correlações entre os dois tipos de redes, construímos uma matriz onde identificamos para cada autor a quantidade de artigos que publicou, a quantidade 
de grupos de trabalho que participou e o seu grau de centralidade na rede de coautoria, considerando as três medidas de centralidade apresentadas na seção 2. Utilizamos para a análise dessas correlações o coeficiente linear de Pearson. Consideramos as visualizações de redes apresentadas, bem como as inferências de suas correlações como indícios fundamentais que nos permitiram descrever algumas das estratégias de conectividade utilizadas pelos autores em seus processos de produção científica e articulação dessa produção com outros autores, bem como com os grupos de trabalho propostos pela organização do evento.

\section{RESULTADOS}

É importante mencionarmos que as informações coletadas representam os anais do evento do ano de 2003 ao ano de 2009, sendo que não houve sua realização no ano de 2004, logo não havendo dados relativos a esse período.

Em relação ao processo de tratamento e seleção dos dados para análise, coletamos 845 registros disponíveis nos anais online, sendo que de início 5 registros foram descartados, onde 3 não indicavam os nomes dos autores, 1 não indicava o grupo de trabalho onde o trabalho foi apresentado e 1 trabalho estava datado do ano de 2004, quando não houve realização do encontro, terminando com 840 artigos válidos para análise. Identificamos um total de 993 nomes de autores diferentes presente na base de dados, sendo que finalizamos o processo de normalização dos nomes com 912, representando uma redução de 8,16\% da quantidade original. Dos 912 autores, $806(88,38 \%)$ realizaram ao menos uma parceria de coautoria e apenas 106 (13,15\%) publicaram sem nunca terem estabelecido conexão com outros autores.

Apresentamos na tabela 1, a seguir, o modo como se dá a distribuição de grupos de trabalho, artigos e autores pelos anos de realização do encontro. Vale frisar que a quantidade de autores é maior do que o número total de autores únicos na base de dados, indicando que vários autores participaram mais de uma vez.

\begin{tabular}{|c|c|c|c|}
\hline Ano & Gts & Artigos & Autores \\
\hline 2003 & 8 & 138 & 226 \\
\hline 2005 & 7 & 123 & 195 \\
\hline 2006 & 7 & 102 & 175 \\
\hline 2007 & 7 & 171 & 276 \\
\hline 2008 & 9 & 151 & 279 \\
\hline 2009 & 9 & 155 & 271 \\
\hline Total & & $\mathbf{8 4 0}$ & $\mathbf{1 4 2 2}$ \\
\hline
\end{tabular}

Tabela 1. Distribuição de grupos de trabalho, artigos e autores. 
Notamos que a quantidade de autores varia de um máximo de 279 participantes no ano de 2008 a um mínimo de 175 participantes no ano de 2006, parecendo se manter relativamente estável a quantidade de participantes nos 3 últimos anos analisados.

O número máximo de artigos publicado com a participação de um mesmo autor ao longo de toda a história do evento descrita nos anais foi de 13 artigos, sendo que apenas um autor publicou essa quantidade de trabalhos. Apresentamos na tabela 2, a seguir, como ocorreu essa distribuição de quantidades de artigos publicados pelos autores participantes.

\begin{tabular}{|c|c|c|}
\hline Quantidade de artigos & Autores & $\%$ \\
\hline 1 & 624 & $68,42 \%$ \\
\hline 2 & 143 & $15,58 \%$ \\
\hline 3 & 41 & $4,50 \%$ \\
\hline 4 & 30 & $3,29 \%$ \\
\hline 5 & 19 & $2,08 \%$ \\
\hline 6 & 14 & $1,54 \%$ \\
\hline 7 & 13 & $1,43 \%$ \\
\hline 8 & 11 & $1,21 \%$ \\
\hline 9 & 8 & $0,88 \%$ \\
\hline 10 & 4 & $0,44 \%$ \\
\hline 11 & 3 & $0,33 \%$ \\
\hline 12 & 1 & $0,11 \%$ \\
\hline 13 & 1 & $0,11 \%$ \\
\hline
\end{tabular}

Em torno de $70 \%$ dos autores que participaram do ENANCIB publicaram apenas um trabalho nos anais, sendo que apenas 55 (6\%) autores participantes publicaram de 5 a mais trabalhos. Já em relação a como ocorreu a participação desses autores nos grupos de trabalho, apresentamos essa distribuição na tabela 3, a seguir.

\begin{tabular}{|c|c|c|}
\hline Número de Gts & Autores & $\%$ \\
\hline 1 & 720 & $78,95 \%$ \\
\hline 2 & 125 & $13,71 \%$ \\
\hline 3 & 42 & $4,61 \%$ \\
\hline 4 & 20 & $2,19 \%$ \\
\hline 5 & 5 & $0,55 \%$ \\
Total & $\mathbf{9 1 2}$ & $\mathbf{1 0 0 , 0 0} \%$ \\
\hline
\end{tabular}

Tabela 3. Distribuição de autores pela quantidade de grupos de trabalho que participaram.

Em torno de $80 \%$ dos autores publicou seus trabalhos em apenas um grupo, sendo que apenas 67 (em torno de 7\%) autores publicou algum trabalho em 3 ou mais grupos, no entanto, não 
passando nenhum autor a participar mais do que 5 grupos de trabalho. Finalizando essa descrição inicial de nossa base de dados, apresentamos na tabela 4, a seguir, como se deu a distribuição da quantidade de autores por grupos de trabalho e na tabela 5, a distribuição de coautoria pelos trabalhos publicados.

\begin{tabular}{|c|c|}
\hline GTS & Autores \\
\hline GT1 & 109 \\
\hline GT2 & 193 \\
\hline GT3 & 190 \\
\hline GT4 & 169 \\
\hline GT5 & 134 \\
\hline GT6 & 129 \\
\hline GT7 & 156 \\
\hline GT8 & 94 \\
\hline GT9 & 24 \\
\hline
\end{tabular}

Tabela 4. Distribuição da quantidade de autores participantes dos grupos de trabalho

Vale dizer que a análise da distribuição de autores por grupo de trabalho deve levar em consideração o tempo de existência desses grupos, sendo os GTs 8 e 9 os mais recentes na organização dos ENANCIBs em relação aos demais de nossa análise, logo tendo menos anos que ocorreram e, portanto, menos autores que tiveram a possibilidade de submeter seus trabalhos para esses grupos.

\begin{tabular}{|c|c|c|}
\hline Autores & Trabalhos & $\%$ \\
\hline 1 & 292 & $34,76 \%$ \\
\hline 2 & 389 & $46,31 \%$ \\
\hline 3 & 92 & $10,95 \%$ \\
\hline 4 & 35 & $4,17 \%$ \\
\hline 5 & 14 & $1,67 \%$ \\
\hline 6 & 12 & $1,43 \%$ \\
\hline 7 & 3 & $0,36 \%$ \\
\hline 8 & 2 & $0,24 \%$ \\
\hline 9 & 1 & $0,12 \%$ \\
\hline Total & $\mathbf{8 4 0}$ & $\mathbf{1 0 0 , 0 0 \%}$ \\
\hline
\end{tabular}

Tabela 5. Distribuição da quantidade de autores por trabalhos publicados 
É interessante notarmos na tabela 5 que 34,76\% da produção científica analisada foi escrita por apenas um autor, sendo que a grande maioria dos trabalhos foi realizada em coautoria entre 2 até 9 autores em um mesmo trabalho. 0 maior índice de coautoria foi de 2 autores por trabalho, atingindo mais de $46 \%$ dos trabalhos.

Veremos a seguir o modo como os dados apresentados podem ser relacionados com a estrutura das redes sociais modo 1 e modo 2 aqui em estudo. Analisando agora o modo como essas redes estão estruturadas, destacando nas cores dos nós a quantidade de grupos de trabalho que cada autor participou, apresentamos na figura 4, a seguir, a rede de coautoria de todos os participantes dos anais em análise.

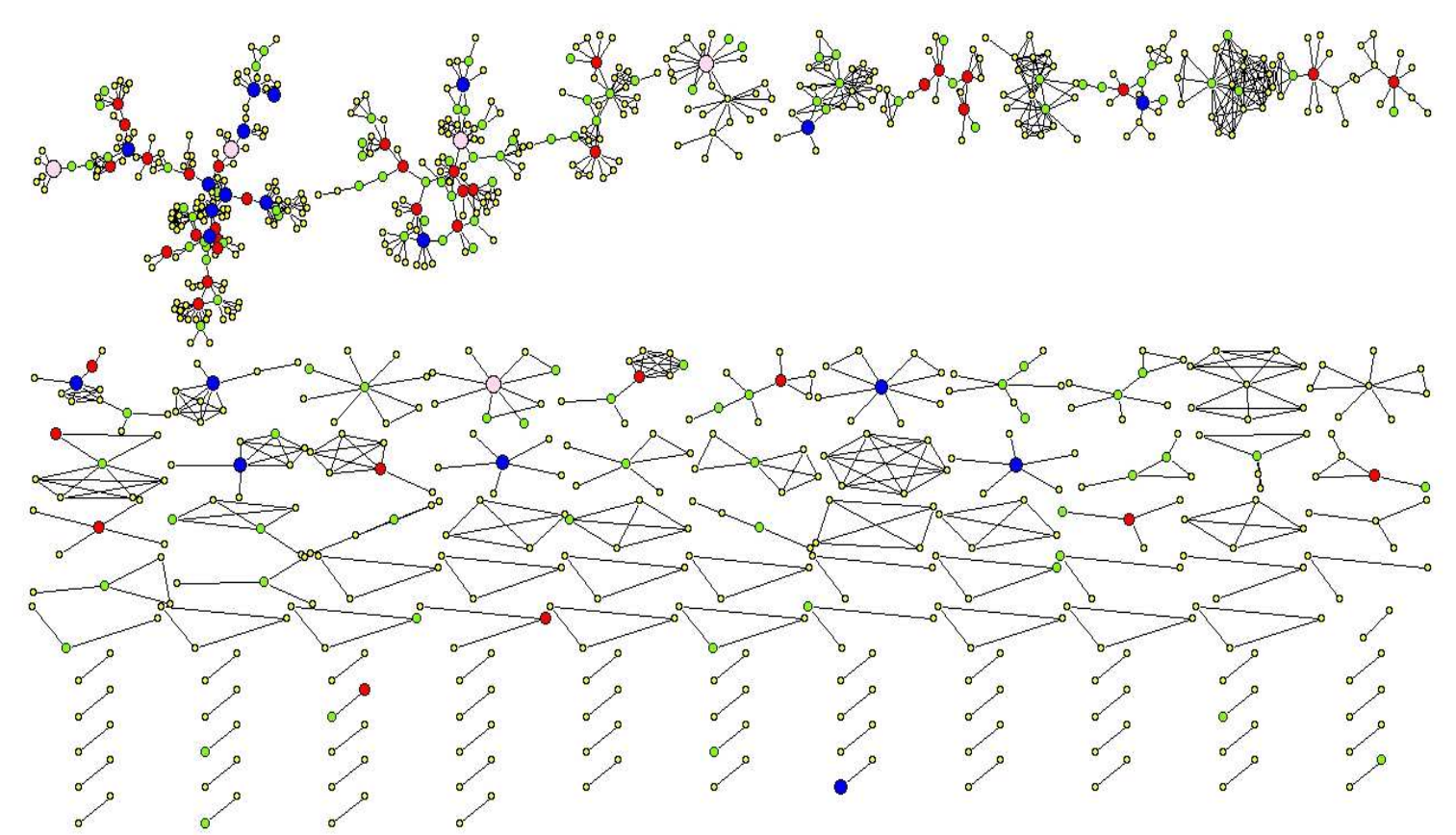

Figura 4. Rede de coautoria dos anais do ENANCIB. Legenda por número de participações em grupos de trabalho: rosa (5 Gts), azul (4 Gts), vermelho (3 Gts), verde (2 Gts), amarelo (1 Gt).

É importante ressaltarmos algumas das características estruturais da rede apresentada. Inicialmente, a rede é composta de vários componentes, representados pelos pedaços que não possuem conexão direta entre si. Esses componentes podem ser entendidos como grupos que, na relação específica de coautoria, atuaram de forma isolada, não criando relações diretas de colaboração na produção científica entre si. É interessante ressaltarmos que dos 5 autores que mais participaram de grupos de trabalho, ou seja, que atuaram ao longo de sua história de participação em 5 grupos de trabalho ao todo, estão distribuídos em 4 componentes da rede, onde em um deles 
$2(40 \%)$ desses autores estão conectados por conexões indiretas. Já dos 20 autores que participaram de 4 grupos de trabalho, notamos uma concentração de 9 (45\%) deles no maior componente da rede, onde esses autores ocupam as posições centrais de articulação de outros nós desse componente, e os outros 11 distribuídos por outros 10 componentes por toda a rede. 0 maior componente da rede parece concentrar em torno da metade dos autores que mais participaram de grupos de trabalho em seus níveis de atuação, sendo o restante deles espalhados por diferentes componentes.

Apresentamos a seguir, na figura 5, a rede de participação dos autores nos grupos de trabalho do evento. Vale lembrar aqui que essa rede é construída considerando o grupo de trabalho como um tipo de nó na rede e os autores como outro tipo de nó, não existindo, portanto, conexão direta entre autores, mas apenas entre eles e seus respectivos grupos onde tiveram algum trabalho publicado nos anais.



Figura 2. Rede de participação nos grupos de trabalho dos anais do ENANCIB. Legenda:azul ciano (grupos de trabalho), rosa (5 Gts), azul (4 Gts), vermelho (3 Gts), verde (2 Gts), amarelo (1 Gt).

Novamente, é importante ressaltarmos aqui algumas das características estruturais dessa rede. Os grupos de trabalho são representados pelos maiores nós da rede, demarcados em azul ciano. Os outros nós, conforme especificados nas cores da legenda da figura, são autores coloridos pelo quantidade de participação em diferentes Gts onde apresentaram seus trabalhos. Como era de se esperar, os nós que garantem o maior nível de conectividade entre todos os grupos de trabalho são aqueles que participaram de 5, 4 e 3 Gts, sendo apresentados na imagem acima nas cores rosa, azul e vermelho e ocupando a posição central de articulação entre os Gts. Conforme a tabela 3, 
estamos analisando aqui um universo de 67 pesquisadores que estruturalmente são responsáveis por essa configuração que aqui apresentamos.

Analisamos agora o modo como essas configurações em termos de posição de centralidade na rede de coautoria, participação em grupos de trabalho e quantidade de trabalhos publicados se relacionam entre si, buscando, desse modo, indicarmos algumas das estratégias de articulação que podem ser descritas a partir dos padrões de conexão que aqui identificarmos. Apresentamos na tabela 6 os resultados da correlação, onde destacamos com a cor vermelha as correlações que apresentam maiores índices de relação linear.

\begin{tabular}{|c|c|c|c|c|}
\hline & Trabalhos & Grau & VIzInhança & Intermediaçao \\
\hline Trabalhos & - & 0,67 & 0,31 & 0,59 \\
\hline Gts & 0,80 & 0,50 & 0,27 & 0,38 \\
\hline
\end{tabular}

Tabela 6. Matriz de correlação - Centralidades da rede de coautoria e Gts da rede de participação em grupos de trabalho.

Os resultados indicam importantes aspectos que nos ajudam a compreender melhor como estruturalmente a rede foi construída em relação ao modo pelo qual os autores articularam sua produção científica e participação nos grupos de trabalho. A correlação mais forte indicada, de 0,80 , ocorre em relação a quanto mais grupos de trabalho um autor participa, mais trabalhos ele tem publicado. Relação que já era de se esperar, dado que quanto mais grupos ele participa, ao menos um trabalho em cada grupo o autor deve encaminhar. Quanto mais trabalhos um autor publica maior é sua centralidade por grau de conexão direta com outros autores, apresentando uma correlação de 0,67. Essa relação também era de se esperar, dado que sabemos pela tabela 5 que em torno de $65 \%$ dos trabalhos publicados são em coautoria, ou seja, quanto mais trabalhos um autor publica maior é a chance dele estabelecer conexões com outros autores, dado que a maioria dos trabalhos não é publicada por apenas um autor. Em termos de grupos de trabalho e centralidade por grau, também notamos uma correlação mediana, mostrando que quanto mais grupos um pesquisador participa, mais trabalhos ele publica e quanto mais trabalhos publica mais conexões estabelece entre pessoas.

Já na centralidade por vizinhança não notamos nenhuma correlação considerável, indicando que o fato de um autor publicar mais trabalhos e/ou participar de mais grupos de trabalho não necessariamente o torna muito mais próximo de todos os outros nós da rede. Essa característica é perceptível em redes onde temos um alto nível de fragmentação em diferentes componentes, ou seja, não há caminho direto entre os nós que atuam em componentes diferentes, fazendo com que esses nós sejam significativos apenas no contexto do componente da rede no qual atuam. 
No caso da centralidade por intermediação, já notamos um padrão diferente. Há uma tendência considerável de que quanto mais trabalhos um autor publica, mais intermediário ele se torna na rede em relação as todas as conexões, ou seja, mais ele se torna uma posição importante de articulação no caso de apresentar dois autores que ainda não tenham estabelecido uma conexão direta. É também curioso notar que no caso da quantidade de Grupos de trabalho isso não ocorre, indicando que participar de mais Grupos de trabalho não torna o autor necessariamente um maior articulador entre os demais participantes da rede.

A partir dos resultados acima apresentados, podemos agora estabelecer alguns princípios que parecem orientar o processo de formação da rede de autores participantes do ENANCIB:

- a atuação em mais grupos de trabalho não cria necessariamente maior conexão entre um autor e outros participantes daquele grupo, ampliando a articulação entre eles;

- os autores que mais participam em grupos de trabalho não estão conectados diretamente entre si, formando um grupo dos maiores articuladores do evento. Eles estão conectados em diferentes componentes distribuídos pela rede, indicando muito mais um nível de articulação local com seus colaboradores imediatos e que se manifesta no evento como um espaço de exposição do trabalho local realizado do que com os outros autores mais atuantes;

- o maior componente da rede conta com aproximadamente metade dos autores que atuaram em mais grupos de trabalho, porém mesmo nesse componente esses autores não estão conectados diretamente entre si, como podemos visualizar na figura 4 . Ao que tudo indica pela estrutura da imagem, esse maior componente é formado quando autores parceiros desses que participaram de mais grupos de trabalho se conectam com outros que se encontram na mesma condição;

- no entanto, no maior componente da rede, identificamos que no centro deste a rede se mantém integrada por poucas conexões, estabelecidas majoritariamente por 3 nós de coloração vermelha, ou seja, pesquisadores que participaram de 3 grupos de trabalho. Sem as conexões desses nós no centro do componente, o mesmo seria fragmentado em 4 partes. Esses nós terminam por exercer um importante papel na integração dessas partes, se tornando importantes intermediários no campo de articulação das conectividades na rede. Vale destacar que nesse mesmo componente, o mesmo papel não é percebido nos participantes de coloração rosa, atuantes em 5 grupos de trabalho. Seu papel estrutural nesse componente caracteriza uma ação de intermediação mais local do que central.

- as relações de coautoria entre dois autores parecem ser mais influenciadas por questões locais de articulação, tais como relações entre orientador e orientando, bem como possíveis 
participações em grupos de pesquisa locais de suas instituições de origem. A estrutura da rede revela que o evento permite o encontro desses grupos, onde os mesmos exibem seus trabalhos, compartilham conhecimento, debatem questões e, pontualmente, estabelecem novas parcerias de trabalho, não sendo esta situação majoritária;

- e, por fim, os autores que publicam mais trabalhos ocupam posições mais centrais na rede do que os autores que participam de mais grupos de trabalho onde divulgam sua produção, evidenciando novamente que a participação em grupos de trabalho não necessariamente se reverte em maior nível de articulação na rede de autores.

\section{CONCLUSÕES}

As evidências coletadas e apresentadas neste artigo nos mostram que o uso integrado da modelagem de redes sociais modo 1 e modo 2 para análise das estratégias de articulação de pesquisadores nas relações de coautoria em sua produção científica e na participação em grupos de trabalho permite identificarmos diversos eventos e padrões estruturais de articulação entre eles.

O uso da correlação linear entre os indicadores de centralidade das redes sociais e as os dados descritivos de nossa base de dados permitiram encontrar efeitos que parecem apontar relações de causalidade em seus padrões de ocorrência. Desse modo, pudemos identificar com maior clareza os efeitos de participação em mais grupos de trabalho e da publicação de mais trabalhos científicos nas diferentes posições estruturais de centralidade aqui analisadas. Evidências dessa análise nos mostraram que a articulação de um pesquisador em sua rede se dá mais pelo fato de ter publicado mais trabalhos do que ter participado em mais grupos de trabalho. Ao publicar mais trabalhos, os pesquisadores criam mais relações entre si que não necessariamente são geradas pelo fato de participarem de mais grupos de trabalho, onde ali podem estar presentes apenas representando suas redes de articulação institucional local.

É importante ressaltar que outras pesquisas analisando como essas conexões ocorrem ao longo do tempo nos permitiriam identificarmos a dinâmica de formação dessas redes modo 1 e modo 2, ampliando nosso potencial de análise para possivelmente identificarmos eventos singulares ocorridos em cada ano de realização do evento que contribuíram para a constituição estrutural das redes aqui apresentadas. Em trabalhos futuros, analisaremos a dinâmica dessas redes buscando identificar esses eventos singulares. Além disso, dado que as articulações locais parecem ser uma estratégia fundamental de nossos resultados, pretendemos mapear as instituições de origem dos pesquisadores, procurando estudarmos as redes em novas configurações onde os nós possam ser 
agrupados por instituições e observamos que efeitos esses agrupamentos apresentam nos padrões estruturais e dinâmicos de nossa análise.

\section{Referências}

ANCIB, Sobre a Associação Nacional de Pesquisa e Pós-graduação em Ciência da Informação. Em: < http://www.ancib.org.br/pages/sobre.php >. Acesso em: 14 de junho de 2012.

ANCIB, Anais do ENANCIB. Em: <http://www.ancib.org.br/pages/anais-do-enancib.php >. Acesso em: 10 de abril de 2012.

BUFREM, Leilah Santiago, GABRIEL JUNIOR, Rene Faustino, GONÇALVES, Viviane. Práticas de coautoria na processo de comunicação científica na pós-graduação em Ciência da Informação no Brasil. Inf. Inf., Londrina, v. 15, n. esp., p. 110-129, 2010.

CARMO , João dos Santos, PRADO, Paulo Sérgio Teixeira. Apresentação de trabalho em eventos científicos: comunicação oral e painéis. Interação em Psicologia, v. 9, n. 1, p. 131-142, jan./jun. 2005.

GLÄNZEL, Wolfgang, THIJS, Bart. Using 'core documents' for detecting new emerging topics. Proceeding of the ISSI 2011 Conference, Durban, South Africa, pp. 224-235.

IBICT, Sobre o Encontro Nacional de Pesquisa em Ciência da Informação. Em: <http://enancib.ibict.br/ >. Acesso em: 14 de junho de 2012.

LEYDESDORFF, Loet. The challenge of Scientometrics: the development, measurement, and selforganization of scientific communications. DSWO Press, Leiden University, 2001. 344p.

MARTELETO, Regina. Redes sociais, mediação e apropriação de informações: situando campos, objetos e conceitos na pesquisa em Ciência da Informação. Pesq. Bras. Ci. Inf., Brasília, v.3, n.1, p. 27-46, jan./dez. 2010.

MEADOWS, A. J. A comunicação científica. Brasília: Briquet de Lemos, 1999. 268p.

NOOY, Wouter de, MRVAR, Andrej, BATAGELJ, Vladimir. Exploratory social network analysis with Pajek. New York: Cambridge University Press, 1994. 334p.

PISCIOTTA, Kátia. Redes sociais: articulação com os pares e com a sociedade. In: POBLACION, Dinah Aguiar, WITTER, Geralina, SILVA, José Fernando Modesto (org.). Comunicação e produção científica: contextos, indicadores, avaliação. São Paulo: Angellara, 2006. p. 115-135.

VANZ, Samile Andrea de Souza, STUMPF, Ida Regina Chittó. Colaboração científica: revisão teóricoconceitual. Perspectivas em Ciência da Informação, Belo Horizonte, v. 15, n.2, p. 43-55, maio/ago. 2010.

WASSERMAN, Stanley, FAUST, Katherine. Social network analysis: methods and applications. New York: Cambridge University Press, 1994. 825p. 